\title{
Early Ethical Assessment: An Application to the Sustainability of Swine Body Scanners
}

\author{
Paul B. Thompson ${ }^{1, *}$, Laurie Thorp ${ }^{1}$, Blake L. Ginsburg ${ }^{2}$, Tabitha Maria Zivku ${ }^{3}$ and Madonna Benjamin ${ }^{4}$ \\ 1 Department of Community Sustainability, College of Agriculture and Natural Resources, \\ Michigan State University, East Lansing, MI 48824, USA; thorpl@msu.edu \\ 2 Department of Philosophy, College of Arts and Letters, Michigan State University, East Lansing, MI 48824, \\ USA; ginsbu16@msu.edu \\ 3 Program in Environmental Studies, New York University, Manhattan, NY 10003, USA; \\ zivkutabitha@gmail.com \\ 4 Department of Large Animal Clinical Services, College of Veterinary Medicine, Michigan State University, \\ East Lansing, MI 48824, USA; gemus@msu.edu \\ * Correspondence: thomp649@msu.edu
}

Citation: Thompson, P.B.; Thorp, L.; Ginsburg, B.L.; Zivku, T.M.; Benjamin, M. Early Ethical Assessment: An Application to the Sustainability of Swine Body Scanners. Sustainability 2021, 13, 14003. https://doi.org/ $10.3390 /$ su132414003

Academic Editors: Thomas P. Tomich and Casey Hoy

Received: 27 October 2021

Accepted: 13 December 2021

Published: 18 December 2021

Publisher's Note: MDPI stays neutral with regard to jurisdictional claims in published maps and institutional affiliations.

Copyright: (c) 2021 by the authors. Licensee MDPI, Basel, Switzerland. This article is an open access article distributed under the terms and conditions of the Creative Commons Attribution (CC BY) license (https:/ / creativecommons.org/licenses/by/ $4.0 /)$.

\begin{abstract}
An early ethics assessment method was used to evaluate sustainability goals and early findings from an automated body scanning technology for swine production. The project had twin goals of discovering potential pitfalls in the technology and exploring the applicability of the method, derived from the Ethical Matrix, as a tool to aid researchers in product design at very early stages in the research and development $(R \& D)$ process. This paper reports results on the second objective. Results of the evaluation workshop were coded and qualitatively analyzed. These results are reported and compared; the exercise is compared to the findings of other researchers using more traditional methods for ethical assessment on similar technologies, as well as standard social science methods for ascertaining economic sustainability and social acceptability of technological innovations. We conclude that the method has promise, especially for its applicability at very early stages in R\&D, but that it does not substitute for analyses that occur at a much later stage in product or procedural development.
\end{abstract}

Keywords: precision livestock production; automated sensors; technology assessment; social sustainability; agricultural ethics

\section{Introduction}

The connections among innovation, oversight of technology and sustainability are complex, especially in the domain of agriculture. On the one hand, exhaustion of soil and water resources combines with the impact of climate change to undercut existing agricultural practices in many regions of the world. Rising sea levels will cover lands currently used for farming and animal grazing in coastal areas. Change in ocean temperatures and currents contributes to dramatic declines in the stock of fish. In order to sustain a global population, food producers will be forced to make changes in their technical approach because their current methods are expected to become increasingly unreliable [1]. The convergence of artificial intelligence, big data, robotics and biotechnology is poised to introduce a stream of technical innovations designed to meet these challenges in the food sector [2]. These developments are fueled by an infusion of venture capital in innovative and disruptive technologies for food production [3].

On the other hand, sustainable agriculture was initially defined in terms of low-input farming systems and an emphasis on producer management skills rather than capitalintensive technology [4]. This approach continues to be influential [5] and sustainable agriculture continues to be represented as an alternative style of food production that minimizes the use of many advanced technologies [6,7]. Innovations that are beneficial 
in response to climate change may also have the potential to disrupt local food systems when smallholders lack the resources to access them, for example, when their impact on commodity markets incentivizes so-called "land grabs" or when governments encourage shifts to high technology systems through subsidies, tax policy or partnerships with innovating firms $[8,9]$.

The tension between views of sustainable food production that emphasize feeding urban populations while minimizing environmental impact and those that stress the continued viability of smallholders and rural communities becomes even more complex in the livestock sector, where impacts on the animals themselves becomes important for sustainability. Technologies for increasing the cost efficiency of animal production are alleged to compromise the welfare of farmed animals [10]. A 2013 policy forum in Science argues that animal welfare must be included in the indicators for sustainable intensification of livestock production [11]. This objective is itself complicated by the diversity in governance styles. State regulation, voluntary guidelines and market-based incentives function interactively to shape the development of animal welfare standards.

Another difficulty in assessing the sustainability of innovative agricultural technologies derives from consumer resistance to the first generation of genetically engineered food technologies. A coalition of activists drawn from environmental groups, animal advocacy, consumer protection organizations and opponents of rDNA-based gene technologies (many of whom associated biotechnology with racist and anti-life elements of eugenics) was successful in preventing engineered crop varieties from penetrating European markets. They joined with activists supporting small-scale and organic producers to retard the adoption of these same crops in less industrialized regions [12]. Even before these events, protocols for technology assessment started to be conjoined with a call for increasing the role of non-specialists in the assessment process [13,14], but the European public's hesitancy over genetically engineered plants prompted scientific research agencies to fund studies intended to surface doubts, concerns and ethical issues much earlier in the innovation process [15]. Governance of both intended and unintended consequences came to be seen as an important component of social sustainability $[16,17]$.

This paper focuses on a specific assessment methodology designed to surface potential challenges at a very early stage in technology development. Early ethical assessment is a qualitative method for articulating and recording the potential for complaints and criticism of innovations well before key R\&D tasks have been completed, and hence before governance challenges, environmental risks or threats to social sustainability are known. This problem has been referred to as Collingridge's Dilemma; one cannot know the problems with a technological system at the early stages when developers have the greatest flexibility to alter features in its functionality or design [18-20]. Our approach to early ethical assessment adapts the ethical matrix - a heuristic developed for collaborative reviews in bioethics - to rapid assessments and early guidance of the research process. The ethical matrix can be and has been used as a method for generating precautionary ethical evaluations of innovations [21,22]. Buckley, Thompson and Whyte [23] argue that this makes the matrix especially useful as a tool for bringing information on social sustainability to researchers' attention well before irreversible decisions on the trajectory of technology have been made. Although used widely in Europe, the ethical matrix has rarely been applied in the North American context.

The paper summarizes the literature on the ethical matrix and discusses one utilization applied to a precision agriculture research activity in Michigan State University's College of Veterinary Medicine. As discussed below, automated sensing technology can potentially improve the management of veterinary health in food animal production systems, but specific features of implementation could present challenges to adoption by producers (e.g., economic sustainability) and to consumer buy-in (e.g., social sustainability). The following sections establish a further background for ethical methodology and a context in which automated sensing technologies are being developed in livestock production; the results of a half-day early ethical assessment workshop using the ethical matrix are also 
reported. Consistent with the goals of the ethical matrix, these results express an ethical evaluation of the planned research project. The workshop findings on the technology are summarized, but the primary focus of the analysis is to identify the strengths and weaknesses of the ethical matrix rather than to report on the sustainability of automated sensing tools. To this end, the findings of the workshop are compared to independently conducted ethical analyses of sensing technologies in livestock production, followed by a qualitative reflective evaluation of the methodology as applied to this particular study.

\section{Early Ethics Assessment: Materials and Methods}

Early ethics assessment is one of many recently developed tools for anticipating the unintended consequences of innovations, as well as the potential for public opposition to novel technology. Demand for such tools has multiple origins. During the 1970s, several widely publicized biomedical and psychological studies resulted in harm to research subjects. The Belmont Report by a U.S. National Institutes of Health group commissioned to study these episodes recommended case-by-case ethical oversight of all protocols involving human subjects. These recommendations form the basis both for human subjects institutional review boards (IRBs) and for the emergence of bioethics as a discipline within biomedical research and education [24]. Quite separately, Rachel Carson's Silent Spring publicized harmful effects of agricultural pesticide use. By the 1990s, hesitancy over technological innovation was being viewed as a widespread social phenomenon retarding the uptake of nuclear power, genetic engineering and new chemical techniques in a variety of fields [25]. The response to this social phenomenon has included calls for research on anticipatory governance [26], responsible innovation [27] and broader impacts [28].

Although methods for responding to the challenges of research misconduct and resistance to new technology differ in their details, all incorporate explicit, reflective consideration of both the potential impact of practice and its ethical significance. A guidance framework for ethical reflection, called principlism, emerged from the Belmont Report. Principlist methods have been applied by IRBs throughout biomedical research. More thorough principlist reviews might be developed within a research team developing a specific technology. A typical review may convene physicians, technical specialists and representatives from patient groups with bioethicists to conduct an extended conversation on a particular treatment or technical procedure. The group works systematically through four principles, discussing how the treatment or procedure could raise ethical issues with respect to each. The four principles are:

Benevolence: The benefits or goods that affected parties will enjoy as a result of the technology's implementation or use.

Non-Maleficence: A principle derived from the medical principle "Do no harm". Adverse impacts, compromises to welfare and harm experienced by affected parties as a result of the technology's implementation or use.

Autonomy/Dignity: The ways in which an affected party's freedom or fate is limited or compromised by use (or even existence) of the technology. The ways in which the technology might result in a failure to respect these beings or persons for who and what they are.

Justice: The ways in which use of the technology or its aftermath might be considered unfair. Ethically significant discrepancies in the distribution of benefits and burdens [29].

Professor Ben Mepham, an agricultural scientist at the University of Nottingham, modified the principlist framework so that it would be more relevant to projects that have the potential to impact non-humans, including animals and the broader environment. Mepham also noted that technologies have consequences for third parties in addition to their users and their intended beneficiaries. He treated the four principles listed above as column headers and then added a list of rows headed participants, third parties, non-humans and the environment. This produced a four-by-four matrix. Mepham's approach then modified principlism by creating sixteen cells that participants in an ethical discussion would work through in a systematic fashion to consider how each type of affected party 
might be affected in terms as specified by the four principles of benevolence, non-maleficence, autonomy and justice [30].

Mepham called his procedure the ethical matrix. The matrix is intended to function as a heuristic or rubric for collaborative reflection and discussion, as is reflected in Beauchamp and Childress's use of principlism in medical rounds and IRBs. The rubric is non-directive with respect to the outcome of decision-making; it merely guides collective review by highlighting areas that might be overlooked in conventional marketing or cost-benefit analysis, or omitted in a biological or engineering risk assessment. The ethical matrix has been used widely in Europe to evaluate both large-scale and small-scale innovation projects, many with applications in agriculture [21,22,31-34]. The integration of ethical decision aids into U.S. agricultural contexts has been met with more resistance than in Europe, in part because both scientists and interested publics associate the word "ethics" with one-sided advocacy, distinct from open-ended reflective review [35].

However, the ethical matrix has key strengths when compared to many assessment metrics developed under the auspices of anticipatory governance, responsible innovation, broader impacts and other similar schemes. First, all methods suffer from Collingridge's dilemma: one cannot really know what the impact of specific technology will be at the point when key decisions about it are being made. However, Collingridge's dilemma becomes especially problematic for technology assessments that require high levels of public involvement because members of the public have difficulty imagining how a piece of technology will function. By incorporating participants with background expertise, the ethical matrix has the potential to reduce this problem, though it cannot be eliminated entirely. Second, unlike other methods, results from an early application of the matrix approach can function as inputs into the research process, as opposed to ex-post evaluation of a project. Finally, by relying heavily on a network of individuals with specialist knowledge, the matrix permits more rapid assembly of a convenient population for elicitation of data. This both reduces costs and allows for more timely production of results, but at the sacrifice of representativeness and certain inclusion criteria. For these reasons, our adaptation of the ethical matrix for this project emphasizes early assessment. Distinct from assessments that achieve greater representation of stakeholders and more accurate estimates of public acceptability, early assessments provide cost-effective input into a research project at a point where there is greater flexibility to rethink and redesign key elements.

Our application of the early ethics assessment methodology was applied to automated body sensors intended to address technical challenges that occupy the immediate attention of producers and veterinary caregivers. More than one-half of swine breeding females in the US are culled or die each year. The ten-year average of sow and gilt cull and death rate is 53.74 percent and rising [36]. Sow lifetime factors of culled sows include correlations with thin body composition and locomotion problems [37]. In one study, many females with low body condition (composition) scores were culled after they gave birth or weaned their first litter [38]. Additionally, 20\% of the deaths were among sows that had not given birth to their second litter. Lameness was associated with the highest cause of mortality in gilts and young sows [36]. As the female break-even cost is typically at or after their third litter, these losses of younger females from the sow herds are common and both a welfare cost, meaning the producer is not reaching a return to investment. These figures reflect significant opportunities to make technical improvements in both animal welfare, health and the profitability of pork production. When individual animals with health issues are identified, a number of feed, housing or therapeutic mitigation strategies can be available.

The precision agriculture project reviewed in our study is intended to equip pork producers with new tools for identifying animals with potential health issues more quickly and reliably than current husbandry practices allow. The ultimate goal of Madonna Benjamin's project is to develop a software program that will be coupled to a low-cost image capture system. The developed algorithm for the image output will reduce the complex data to a simple score that is meaningful and understood by all farm workers. Such a tool in the arsenal of Precision Livestock Farming will add automated "eyes" and 
knowledge transfer through videos, scoring, certification, performance and economic return. However, as with all agricultural technologies, early identification tools must compete with other factors for the farmer's time, pocketbook and presence of mind $[39,40]$. Responses such as feed modification or treatment of sows are only possible within an overall approach that offers economic incentives to farmers and pharmaceutical and feed industries. Furthermore, actors in each of these sectors may need additional education to utilize novel technologies.

\section{The Workshop and Its Analysis}

In September of 2018, the authors adapted the ethical matrix approach to an early assessment of Benjamin's approach. The workshop was auxiliary to a grant to Benjamin that was dedicated to preliminary research on an automated system for body scans on pigs. The proposal identified the ethical matrix activity as a low-cost addition to the project intended to surface issues that could threaten the development of the project, retard producer uptake or generate opposition from third party groups. The background for such concerns is discussed in more length below.

As described for the workshop, Benjamin's research is intended to fulfill three objectives. The first is to design a universally applicable sensor-based 3D swine body composition detection system and associated image processing method to non-invasively and automatically access composition for all individual sows on a farm at the end of lactation. Second, research will utilize the obtained body composition information to determine if correlations exist with the current gold standards of body composition assessment and other recorded measures of sow health and fertility. Third, in combination with a technology training program for users, the technology will help reconcile tensions between profitability and the promotion of animal welfare. The ethical matrix workshop was designed in part to estimate stakeholders' receptivity to such an initiative and to surface the need for any changes in the research plan well before irreversible design and development activities made them impossible. In addition, the workshop was expected to be especially useful in helping Benjamin develop a plan for the training phase of the project.

While rapid decision support was the primary rationale for the ethical matrix exercise, the secondary goal of our collaboration was to test the methodology within the context of an American agricultural research institution. As discussed above, the ethical matrix is based on decision support techniques that are intended to provide immediate input without the need for costly data collection and extensive social science analyses. Participants' subjective assessment of the value derived from the workshop is one test of its success. However, objective criteria provide the basis for reporting on the content of the discussion and a post hoc evaluation of the ethical matrix methodology. First, the results of the workshop can be assessed in light of broad criteria for greater public oversight and guidance in the development of new technology. Second, the results can be compared to assessments of similar technologies being generated by other researchers and published in the scholarly literature.

To these ends, a transcript of the exercise was produced, coded and analyzed to identify thematic elements, providing a basis for evaluating the themes or ethical claims that were identified through the ethical matrix assessment. The workshop itself ran for half a day, beginning with lunch on September 20, 2018. Participants for the workshop were recruited through networks of the project investigators. The goal was to assemble a group of individuals with expertise in veterinary health, swine production practices, the economic structure of the hog industry, animal welfare and consumer advocacy and the political economy of food animal production. The target was a group of at least ten but not more than twenty participants. At least in broad terms, these goals were met. The room was set up with voice recorders so that all of the comments made during the workshop could be captured for subsequent coding and qualitative analysis of key themes in the workshop discussion [41,42]. Participants in the workshop were asked to sign a consent form to enable transcription and subsequent coding of the information. 
The workshop commenced with an introduction to the ethical matrix method by Paul Thompson, a member of the project team, who also served as facilitator of the workshop. Madonna Benjamin, lead PI on the project, then gave a 20-minute overview of the research goals of the project, including a discussion and video demonstration of the sow body imaging technology, and a review of the production and animal welfare problems it intended to address. At this point, the workshop was opened for reactions, comments and discussion by participants. Although, as discussed below, there were some participants that made very few comments in the workshop, as a group, participants were not reluctant to engage in imaginative speculations on the strengths and weaknesses of the technology, as well as on both the social and economic barriers that might slow its adoption.

After approximately ninety minutes of unstructured discussion, including questions for Dr. Benjamin, Thompson asked workshop participants to turn their attention specifically to the matrix (see Table A1 in Appendix A). At this point, each cell in the matrix was mentioned and a brief clarification on the type of ethical issues associated with that cell was offered. Workshop participants were then invited to reconsider strengths and weaknesses and to indicate whether any new or underrepresented issues occurred to them in connection with that cell. All authors except Zivku were present at the workshop. Thorp was a participant, and Ginsburg was in charge of recording and technical support. Following the conclusion of the workshop, participants were given the opportunity to fill out openended comment forms offering their immediate evaluation of the workshop. Along with Benjamin's subjective assessment, these statements from participants provide an additional basis for evaluating the matrix.

\section{Results: The Ethical Assessment Workshop}

A qualitative analysis of the workshop transcript was performed to evaluate the use of the matrix in this kind of setting. The content analysis of this data is not intended to be used as a prediction of social sustainability or a representation of public perception of the technology. The workshop itself was instructive in providing Benjamin with an indication of possible ethical implications associated with the technology. Content analysis of transcripts should be understood as a distinct research objective aimed at refining the future use of the matrix. For this analysis, audio recordings from the workshop were sent to a third party for transcription. The transcripts were cleaned and validated by the research team. The data from this portion of the workshop were analyzed following guidelines for the content analysis described by Lincoln and Guba [43], adapted from Glaser and Strauss' [41] constant comparative method whereby transcripts were first open coded by two members of the research team. During open coding, data is "unitized" as a segment of narrative that can stand on its own and hold meaning. The researcher "codes" or identifies these units with notes that identify or indicate emerging categories for the unit of text. These are working themes or categories and will be followed by a comparison of categories or domains, along with further discussion to clarify, conflate or eliminate redundant or irrelevant codes. This is a highly recursive process where new insights subsume old ones, moving up the analytic schema. Once the researchers agreed that codes were stable and coherent, the analysis moved to closed coding. Here, the researchers discussed and finalized the emerging themes according to frequency and, more importantly, the data set evolved from taxonomy and began to take on the shape of an explanatory construction of the event/phenomena [44].

The resulting analysis of the ethical matrix identified approximately 15 themes, some of which were made frequently and held significant import to members of the workshop, while others were mentioned without follow-up from other participants. The analysis resulted in a scheme that sorted the workshop narrative into three categories. The most frequently discussed themes/topics brought up by participants during the ethical matrix discussion were: (1) the suggestion that the technology would allow for more data to be accumulated, which, in turn, would have the potential to improve decision making; (2) the suggestion that the technology was promising, beneficial or positive; (3) the suggestion that 
the technology may be used to increase or improve swine welfare; (4) concerns regarding potential economic costs associated with the technology. In addition, a second set of themes arose with less frequency but nonetheless included topics on which a number of participants felt moved to make contributions. Themes in the last category were either mentioned by only one participant or were dropped quickly with little follow-up from other participants.

Starting with the most frequently discussed themes, many participants stated that the value of body scanners derives from the nature and quantity of information that an automated technology would achieve. One who stressed the uncertainty in current practices stated,

And it's kind of the same thing when you're working on the farm and when you are working with employees and being able to narrow that down and to define what that [body condition score] really is. And this may be a tool I think could help them make those decisions better and take the guesswork out of it.

A second participant stated that more data would not necessarily help decisionmakers: "I think if it catches on, I mean, the sheer amount of data and what you could do with it is so enormous it could be overwhelming". Finally, a third pointed out that algorithms coupled with body scanners would standardize the information by removing the variability associated with human observers: "I think I just have more data that is more consistent, that they can help as a decision making tool".

These comments on the usefulness of data generated by sensing technology were consistent with comments on the essentially beneficial nature of the body scanners from a producer or stockperson's perspective. Participants mentioned ways in which the tool would positively affect people's perception of their ability to do their jobs. For example, one participant saw the tool as giving farmers more power: "Right but maybe on this, with this technology, the farms have more of an ability to drive the bus, instead of having something dictated to them". Another stressed how body scanners would reinforce the professional identity of the animal producer: "I think that as herdsmen, that they would feel better about their job because you are able to sort or cull animals and maybe get them back on their feet, because that's the business you are in".

The ethical matrix explicitly asks participants to consider costs and benefits to nonhumans. Accordingly, several participants articulated the benefits of the technology in terms of improvements to animal welfare. One said, " ... the likelihood that she's [the sow] going to be culled from the herd will or should go down through application of this technology because you are going to be able to measure, observe her more often and more objectively than the current practice". Another made the more ambiguous statement that " ... being able to identify early indicators of lameness would be huge". Though this ability might be interpreted in terms of a producer's economic goals, in context, it appears that the speaker was stressing the ability to make an early intervention to protect animal health.

Notably, the only negatives appearing in the top tier of comments voiced by participants relate to the cost of using automated body scanners:

Producers are not going to be willing or want to see the benefit to putting this into a huge database, unless we can tie it back to benchmarking for the industry.

... they now have to go hire a person that's responsible for the electronic feeding system ... they had to go hire a person that understands electronics and that is a mindset that is different, and that is going to be very different, um, and barns are very hard on electronics and things go wrong.

and see if there's efficiency, so it's just a classic business case. You have the technology, you don't add anything else, you make more money on the other end. That would be the ultimate test.... What are the odds of that? I mean like, one in three trillion or something like that. 
Occasionally, these concerns about the costliness of the technology were stated as a response to other potential benefits: "See you are missing the point. Agriculture is a price taker not a price maker".

A secondary tier of themes/topics were coded less frequently than the above four but are worthy of mention. First, participants expressed concerns about the technology causing a loss of human interaction on swine farms. One stated, "So animal handling. Simply because of the technology, you wanna handle the animal". Another said, "Yeah, as I said before, the alienation of the farmer towards his animals ..." ". These comments reinforced more general statements noting that there might be potential trade-offs associated with using the technology. Among statements expressing positive opinions about the technology's possibilities, some mentioned potential monetary benefits brought about by the technology, while others speculated on the technology's potential for improving farm performance standards. Consistent with previously noted statements about the value of standardized data, one said,

So variability between employees, that you've got the machine that's identifying the range of hogs instead of the individual. So if it were my farm, I would feel good that it wouldn't matter which employee I had in there. They're all able to make a good decision.

Another put this observation in the context of a producer's relationship to his buyers in the meat industry: "So if I can prove to you in an objective way that I identified a lame animal, I treated it and in two days, whatever, the animal is back walking again, wouldn't that go a long way to a packer? To say, yeah, I trust this farmer".

Lastly, a tertiary suite of topics appeared infrequently. They were often mentioned by only one participant and/or never resurfaced in the conversation. Notably, the most negative statements about the potential impacts of sensing technology fall into this category. We note first a suite of comments that discussed the potential for what participants considered to be a misuse of sensing technology. One exchange included statements about how "anti-Ag" individuals might use the technology to target pig farmers.

So we're actually moving away from a performance based production system and moving towards a system that's been forced upon the industry, maybe without the animal science or veterinary science background that's needed. But simply done to preserve social science or to meet the needs of social science, brought on by the outside contributors to the industry.

Yeah, they wanna eliminate animal agriculture. Go look at it, go look at what they believe.

The thread of malevolent use against the industry was also expressed by a participant who stated, "There are those that target animal agriculture, that no matter what we do, they will find a way to take any new technology and make it seem negative in their mind".

Other types of misuse include the concern that the data accumulated by the technology might fall into the wrong hands. One participant stated that "... if somebody hacked your system and started putting in wrong data for animals and you were culling animals based on body condition scores that had nothing to do with reality". Another expressed the concern that the technology might lead to an increase in non-farmers/customers policing farm activities, and a related comment questioned how the technology might be used for auditing purposes. In a different vein, two comments addressed the role that the technology might play in the loss of labor or the displacement of workers:

That raises another question then that I had and I'm not sure from your presentation whether this is going to have a net negative impact on um, the number of workers required to manage a facility. Are we going to displace workers with this product or are we going to still need the same number of workers but they're going to need to be trained in how to use the equipment.

I'm still thinking about this guy that's 65 , that's never embraced the electronics and the information. He's roadkill on the information superhighway... so he gets displaced 
because of this technology. You just have to believe there's gonna be a few people like that, that aren't gonna be able to keep up with the technology.

However, countering these worries was a comment that the technology might play a role in increasing the amount of skilled labor in swine production:

The comment was made that it might make them worse stockmen than they are. It might make them better. It may make some of the employees better because the technology will help them to recognize some of these symptoms over time if it's used properly.

Other infrequently noted concerns about the automated body scanning sensors included the potential for environmental costs associated with the technology, the effect of the technology on food safety, concerns about how it might decrease pig welfare and farmer autonomy, as well as concerns about how it might lead to a loss of human ownership over farming processes or reduce the knowledge/skill of pig farmers. While some of these concerns were noted as general categories of downside risk, with no specific examples, others were voiced in reference to a non-descript "they" who impinges on the producer's freedom:

So they can tell you that you need to at a lower lameness score pull that animal and treat, where you might wait two days ... they can constrain your measurements a lot tighter than you want them at.

Or they tell you that you have to treat that animal, which is an added cost to you.

\section{Other Assessments of Precision Livestock Production: A Comparison}

The small but important literature on the ethics of precision livestock production provides a check on the findings of our early assessment workshop. Published reviews of monitoring and computerized data analysis for the livestock sector appear in materials written for a general audience, as well as peer-reviewed journals in agricultural science and applied ethics. At the general audience end of the spectrum, Calvin Isch writes that precision farming "...naturally turns the animals into objects, and resultantly, the harsh conditions that the animals face are ignored by those who used to look at them as friends" [45]. Three animal welfare scientists conduct a detailed review of whether automated monitoring can deliver benefits to animals [46]. In the ethics literature, Rob Sparrow and Mark Howard list potential impacts associated with technological innovations in agriculture ranging from environmental impact to concentration of farm ownership, concluding that tools of precision farming must be given a careful ethical review [47].

Comparing the themes identified by workshop participants to the claims in the peerreviewed ethics literature provides one basis for evaluating the matrix methodology. Here, we begin with a detailed synopsis of two papers from this literature. The title, "The Quantified Animal: Precision Livestock Farming and the Ethical Implications of Objectification" by a group of Dutch authors, implies that the paper will question whether sensing tools could increase the tendency to view food animals as mere things entailing no obligations of husbandry [48]. In "Technology and responsibility: A discussion of underexamined risks and concerns in Precision Livestock Farming", Ian Werkheiser [49] arrives at conclusions that are similar to those of Sparrow and Howard, though specified in more detail with respect to livestock production.

The Dutch group frames their concerns about objectification within the context of typically stated goals for precision livestock farming. These include the standardization of indicators, the continuous collection of data, the ability to manage production without being physically present in the facility, the saving of labor and the capacity for sharing data with other actors in the supply chain [48] (p. 81). These are consistent with the benefits mentioned in the MSU workshop, though data sharing was not classified as a beneficial outcome in the primary category of themes summarized above. In fact, workshop participants saw this attribute of the data system as both a benefit and a threat. While it could give high-quality producers an opportunity to attract higher prices, it would also allow outsiders to intrude upon producer decision making. These privacy concerns were also noticed in our earlier workshop on automated sensing technology [23]. Importantly, 
the Dutch paper does not purport to identify the full range of ethical considerations pertaining to precision livestock farming. The authors' normative focus is limited to the objectification of animals.

The paper includes an extended discussion of objectification in philosophical literature. They note that "treating as an object" might refer to a consciously adopted malicious attitude or to an unintentional habit based on ignorance or inattention. In the latter case, an entire system of practice creates separation between agents and the parties affected by their actions. This permits actors to forget or ignore that affected parties are beings with a subjective life of their own, beings having intrinsic value worthy of respect. While Immanuel Kant's philosophy stressed the sense in which treating others damages the agent's own autonomy, Bos and coauthors draw on feminist care ethics to argue that damage to the relationship between parties is morally significant. They note that the already-existing system of livestock production involves considerable objectification of animals. Food animals are commodities, rather than individuals having inherent value. Producer attention is so focused on management that the animal itself becomes, in their word, invisible. The question, then, is whether automated body sensors and other forms of precision livestock production exacerbate the already problematic relationship between producers and their animals. Although they note several obvious ways in which the previously noted "benefits" of automated husbandry could further deteriorate the caring relationship that should, on their model, exist between humans and animals, their ultimate evaluation of precision livestock methods is inconclusive. They suggest that the social institutionalization of livestock farming is likely to be more influential than new technology [48].

Werkheiser's description of the rationale for precision livestock production differs from that of the Dutch authors. Werkheiser begins by noting the increased demand for animal foods and the environmental impacts of livestock. These forces weigh in favor of expanding the scale of production systems both for output and for management of environmental impact, but the large number of animals in concentrated animal feeding operations (CAFOs) constrains the producer's ability to perform husbandry practices that are tailored to the needs of individual animals. While benefits noted both by the MSU workshop group and by Dutch authors are consistent with Werkheiser's discussion, his characterization places considerably less emphasis on market forces. Werkheiser then lists the under-examined risks. First is a loss of employment opportunities and farm consolidation. In addition, these monitoring tools can be redeployed for other uses, including monitoring other human beings. To the extent that automated monitoring succeeds in improving animal welfare, it may divert attention from the ethical rationales for limiting or abandoning the consumption of animal products. Werkheiser notes that animal welfare is a composite of veterinary health, affect (or experienced welfare) and species-typical behaviors. Balancing these aspects is itself an exercise in ethical decisionmaking. Sensing technology may be more sensitive to some of these indicators than others, effectively imposing a reductive notion of welfare that amplifies the significance of some indicators at the expense of others. Finally, Werkheiser mentions the relational worries noted by Bos and her coauthors. Like other authors, his overall assessment is that these under-examined risks do not provide a conclusive argument against biosensors in livestock farming. Rather, they function as considerations that need to be taken into account during the development and implementation of the technology [49].

When the concerns noted in these two papers are compared to results from the Michigan State ethical matrix workshop, several points of divergence can be noted. At the MSU workshop, concerns about the relationship between producers and animals were evident in comments on the potential loss of human interaction with animals. Yet this relational concern, paramount in the Dutch article and singled out in a second paper by Werkheiser [50], appears in the secondary group for the MSU workshop. Werkheiser's worries about competing ways to interpret animal welfare were entirely absent from comments by workshop participants. Concerns about the social organization of the livestock sector were not articulated with any degree of clarity at the 2018 workshop. These points of 
divergence suggest that the ethical matrix was of limited value in surfacing issues identified by experts in technological and animal ethics.

\section{Analysis: Learning from the Ethical Matrix}

Given these results from coding and analysis of the workshop transcript, two questions can be asked. First, what does the workshop tell us about the potential for automated body scanners as a tool for making improvements to swine production? Second, what does the workshop tell us about early assessments and the ethical matrix as a tool for anticipatory governance and responsible innovation? Although this paper is addressed primarily to an analysis of the ethical matrix, our team found it difficult to separate these two seemingly discrete questions. In this section, we summarize the lessons learned from this workshop by considering different epistemic standpoints from which these two questions might be asked. The following section compares workshop findings with other published assessments of ethical issues in precision livestock production.

The Matrix and Participatory Technology Assessment. Much of the impetus for anticipatory governance, responsible innovation and incorporating consideration of broader impacts into research and development derives from the desire to include the perspectives and interests of parties that are traditionally excluded. Analysis of the coded transcripts revealed deficiencies in the ethical matrix as a tool for reflecting ethical concerns representative of the broader public. First, it is clear that three speakers dominated the conversation. The people who spoke the most during the discussion seemed to steer the conversation toward the topics upon which they were knowledgeable and in directions that corresponded with their particular interests. Upon reviewing the transcripts, it became clear that one participant who was deeply knowledgeable about swine production and who appeared to have a vested interest in the success and uptake of the proposed technology seemed to steer the conversation in a direction that focused on the potential benefits of the technology. The conversation was also largely dominated by the men in the room. This conversational dominance seems to have effectively silenced a number of women in the workshop. This is striking since there was even representation from men and women in the room. All of these concerns suggest that the workshop facilitation could be improved. One might recommend professional facilitation in subsequent efforts.

Consistent with the ethical matrix's reliance on researcher networks, all of the participants in the room were white, the majority were actively involved in the production sphere of animal agriculture and all but one was American. In addition to this $\mathrm{racial} / \mathrm{professional} / \mathrm{national} \mathrm{homogeneity,} \mathrm{most} \mathrm{(if} \mathrm{not} \mathrm{all)} \mathrm{of} \mathrm{the} \mathrm{people} \mathrm{in} \mathrm{the} \mathrm{room} \mathrm{had}$ college-level education and there did not appear to be representation from other educational levels or economic statuses. This lack of diversity could be problematic for several reasons. First, the reactions elicited during the workshop could not be said to represent public opinion, as key demographic criteria were missing from the study group. Second, racial identity and education could induce forms of implicit bias in respondents' reactions to the proposed technological innovation. For example, members of racial minorities are more sensitive to the potential for hazards that have historically affected racially marginalized groups disproportionately [51].

However, it is important to repeat that early ethical assessment is not intended to provide a snapshot of public opinion, nor is it intended as a predictive tool for estimating the eventual success or failure of a technology. Rather, it is intended only to surface a list of potential concerns, benefits, uses and sources for opposition so that researchers and developers can develop a better-informed R\&D process. The considerations that balance lack of diversity include the cost in both money and time of an ethical matrix as compared to more extensive social science research methods and Collingridge's dilemma that at very early stages in the research process, it may be difficult to elicit meaningful opinions from parties wholly unfamiliar with the technology's potential. Only further research with representative audiences can determine whether the lack of representativeness in early ethical assessment limits its usefulness for purposes that it is designed to address. 
It is also worth noting that no one in the room presented and endorsed a perspective that was critical of animal agriculture in general and there seemed to be a commitment to maintaining the status quo of animal agriculture. The most represented voices in the room seemed to betray nostalgia for the animal agriculture methods and practices of the past, which allowed farmers to operate with little oversight. It also came to our attention that, even after Thompson encouraged the group to discuss the effects that the proposed technology might have with respect to justice for various human and nonhuman stakeholders, no one in the room spoke of any potential justice concerns. It is possible that participants regarded the exercise as an opportunity for strategic manipulation of the evaluative framework. It is also possible that participants had a limited understanding or no background with the construct of justice and felt ill-equipped to enter into a discussion about justice for workers or animals. Whether these limitations of the workshop derive from weaknesses in this particular implementation of the matrix methodology or from vulnerabilities that would haunt any early ethical assessment remains an open question.

Early Evaluations by Decision Makers: At the most basic level, principlist methods are expected to help decision-makers avoid the most egregious ethical errors by moving them through a deliberative reflective exercise in which each element is given explicit consideration. The ethical matrix expands principlism by adding a deliberative review of all stakeholders and affected parties, but the exercise is still intended to support decisions that cannot wait for a more rigorous or data-driven ethical and socio-economic analysis. The MSU experience bears out this expectation. Benjamin reported great satisfaction with the workshop immediately after it was completed, and evaluation forms collected on the day of the workshop support the conclusion that participants felt they had a better understanding of the ethical issues associated with biosensors for monitoring swine health and development.

These subjective evaluations are generally positive, and this contrasts with the flaws that became evident after rigorous and detailed coding of the workshop transcripts. In addition, to the extent that the workshop was intended to function as an early ethical assessment that influences the research trajectory at a more fluid stage, our utilization of a coded analysis itself has flaws. Locating and contracting for external transcription services introduces significant delays in the coding process, especially when the first contractor was unable to complete the work in the timeframe promised. Voice-to-text software could reduce these delays. However, transcription challenges interacted with schedule conflicts among the members of the team that are typical for multi-disciplinary research. This put completion of qualitative analysis behind schedule. Finally, as coding neared completion, the COVID-19 outbreak caused further delay. Under more ideal conditions, qualitative methods can produce results more quickly, but these delays are not atypical for many efforts in team science [52].

One might conclude that simply reading the literature, rather than running an early assessment, is the better approach to responsible innovation. However, the time-lapse between running the workshop, coding the transcript and writing up its results is potentially deceptive. Only one of the papers reviewed above was available in September of 2018. This suggests a more qualified judgment. The value of the early assessment methodology lies not in its ability to produce a publishable analysis of ethical issues in a timely manner but in its ability to inform decision-making at very early stages in a research and technology development program. In short, subjective evaluations of the workshop experience may be more relevant for the goals of a truly anticipatory approach. This does not imply that researchers can simply ignore new analyses as they become available. Finally, it is also worth noting that our workshop surfaced issues not seen in the published literature. Studies on the ethics of precision livestock farming have not been sensitive to producer worries about data privacy and their continuing ability to have control over critical aspects of their operations. To the extent that these concerns are ethically valid, the workshop results do contribute new or underappreciated findings to the ethical assessment of automated sensing technology in livestock production. 
Early Assessment vs. Ethical Analysis. The divergence between the published literature on the ethics of precision agriculture and our workshop results also underlines problems with the non-representativeness of workshop participants and the dominance of a few voices. On one hand, participants in an ethical matrix workshop may bring a form of confirmation bias to the experience. That is, they listen selectively to the discussion, foregrounding statements that tend to support beliefs about the ethical acceptability of the technology that they had prior to participating [53]. Although we are not aware of any studies that evaluate the ethical matrix participants' tendency toward confirmation bias, it is an obvious possibility. Pervasive confirmation bias among participants would thoroughly defeat the purpose of anticipatory technology assessments, principlist bioethics and the ethical matrix. The Ethical Matrix Manual discusses this potential and encourages ways to contain it [54]. On the other hand, a more empathetic listening style not only counteracts confirmation bias but can also overcome apparent problems that are revealed in the coding of our workshop. The relevant difference appears in the way that coding tends to highlight the frequency or intensity of certain themes, while an attentive listener may find infrequently cited observations to be extremely salient. Participants who undertake a more conversational and empathetic listening style are more likely to detect implicit meanings [55]. As such, they may be prepared to make ethically significant inferences based on a single statement. Such listeners may well conclude that the exercise succeeds in opening their minds to noteworthy considerations that they had not hitherto appreciated. However, a subjective success of this sort is unlikely to be reflected in a discourse content analysis.

\section{Conclusions}

Consistent with our focus on the ethical matrix as a tool for early ethics assessment, we do not report conclusions on the sustainability of Benjamin's technology. Viewed strictly as a decision-support tool intended for utilization at an early stage of the research, the immediacy with which results were obtained and the low costs of the method were sufficient to warrant a favorable assessment. The long list of tertiary findings provides researchers with a "dashboard" of factors to monitor as research proceeds, remaining alert to modifications or tweaks that could ameliorate the potential for any of them emerging as significant problems. That is, in fact, exactly what advocates of principlism and the ethical matrix hoped to achieve.

However, decision support is not the same thing as a result publishable in a social science or science policy outlet. Tertiary concerns receiving weak support from a discourse content analysis of a workshop conducted among hand-picked participants with an over-representation of academic professionals and an under-representation of socially marginalized groups do not stand up to peer review. Well-establishebd findings from social psychology suggest that a more representative sample of the American public would have been less sanguine about the likely consequences of any new technology [56]. The fact that the workshop is itself partly funded by the industry makes matters worse [57]. Researchers in our team with an interest in probing the structural biases within the agricultural research establishment (e.g. Thompson, Thorp and Ginsburg) were not surprised at the blandly positive support that this workshop registered for a colleague's research or for the implicit suggestion that producer profitability is the appropriate standard for evaluating its acceptability.

More broadly, our workshop experience suggests that even if any given application of the matrix method fails to either predict sustainability issues or serve as a representative snapshot of public opinion, the methodology does represent an inexpensive way to enhance a technology's sustainability prospects. Consistent with applications of principlist bioethics, a matrix exercise need not involve the elaborate coding undertaken in connection with our project. As agricultural and veterinary researchers become more sensitive to the full range of sustainability concerns-that is, as they become better listeners-one would expect an early ethics assessment using the matrix methodology to enhance the reflective capacity of a research team. 
Author Contributions: Conceptualization, P.B.T. and M.B.; methodology, P.B.T. and L.T.; technical support, B.L.G.; validation, L.T.; formal analysis, B.L.G. and L.T.; data curation, L.T. and T.M.Z.; writing-original draft preparation, P.B.T., B.L.G., L.T., T.M.Z. and M.B.; writing-review and editing, P.B.T. and B.L.G.; supervision, M.B.; project administration, M.B. and T.M.Z.; funding acquisition, M.B. and P.B.T. All authors have read and agreed to the published version of the manuscript.

Funding: The workshop was funded by a university run grants program entitled the Michigan Alliance for Animal Agriculture (MAAA), project M-AAA 18-025. The program combines university funds with contributions from primary (e.g., farm-based) livestock producers. Thompson's contributions were supported by his USDA Hatch Project MICL02324 and by funds from the W.K. Kellogg Foundation funded endowment for the W.K. Kellogg Chair in Agricultural, Food and Community Ethics.

Institutional Review Board Statement: The protocol was reviewed by the MSU IRB, MSU Study ID: STUDY00000351, which made the determination that the research does not involve human subjects.

Informed Consent Statement: All workshop participants gave written informed consent for participation and development of the transcript. The study was conducted in accordance with the Declaration of Helsinki.

Data Availability Statement: Although workshop participants gave permission for publication, raw transcript data has not be published because thorough de-identification would be difficult, and the authors wish to respect the privacy of participants. The qualitative analytic method used in this report does not necessarily imply that generalizations will be replicable. Raw workshop transcripts can be obtained from the corresponding author.

Conflicts of Interest: Benjamin maintains a proprietary interest in the development of the technology discussed in this report. Other authors have no conflicts of interest to declare with respect to the conduct or findings of this study.

\section{Appendix A}

Table A1. The Ethical Matrix.

\begin{tabular}{cccccc}
\hline & Benevolence & Non-Maleficence & $\begin{array}{c}\text { Autonomy/ } \\
\text { Dignity }\end{array}$ & Justice & $\begin{array}{c}\text { This Column Left } \\
\text { Blank }\end{array}$ \\
\hline Participants & $?$ & $?$ & $?$ & $?$ \\
\hline 3rd Parties & $?$ & $?$ & $?$ & $?$ & $?$ \\
\hline Non-Humans & $?$ & $?$ & $?$ & $?$ \\
\hline Ecosystems \& the Environment & $?$ & $?$ & $?$ \\
\hline
\end{tabular}

\section{Key}

Ethical Principles

Benevolence: The benefits or goods that affected parties will enjoy as a result of the technology's implementation or use.

Non-Maleficence: A principle derived from the medical principle "Do no harm". Adverse impacts, compromises to welfare and harm experienced by affected parties as a result of the technology's use.

Autonomy/Dignity: Ways in which an affected party's freedom or fate is limited or compromised by use (or even existence) of the technology. Ways in which the technology might fail to respect these beings or persons for who and what they are.

Justice: Ways in which the use of the technology or its aftermath might be considered unfair. Ethically significant discrepancies in the distribution of benefits and burdens.

Affected Parties

Participants: Developers, purveyors and users of the technology; anyone who is in a position to make decisions about the use or design of the tool. 
3rd Parties: Human beings who might be interested in or affected by the use of the technology in any manner, shape or form, but who are not in the group of participants described above.

Non-Humans: Animals capable of experiencing pain and all other sentient, experiential states, whether the effect is intended or not.

Ecosystems and the Environment: All other types of ethically significant effects, intended to include biodiversity, ecosystem integrity and health, impact on species and other systems crucial to life on planet Earth.

A column has been left blank so that participants can add points they do not see covered elsewhere.

\section{References}

1. Smith, P.; Bustamante, M.; Ahammad, H.; Clark, H.; Don, G.H.; Elsiddig, E.A.; Haberl, H.; Harper, R.; House, J.; Jafari, M.; et al. Agriculture, forestry and other land use (AFOLU). In Climate Change 2014: Mitigation of Climate Change. Contribution of Working Group III to the Fifth Assessment Report of the Intergovernmental Panel on Climate Change; Edenhofer, O.R., Pichs-Madruga, Y., Sokona, E., Farahani, S., Kadner, K., Seyboth, A., Adler, I., Baum, S., Brunner, P., Eickemeier, B., et al., Eds.; Cambridge University Press: New York, NY, USA, 2014.

2. Little, A. The Fate of Food: What We'll Eat in a Bigger, Hotter, Smarter World; Harmony Books: New York, NY, USA, 2019.

3. Graff, G.D.; Silva, F.D.F.; Zilberman, D. Venture capital and the transformation of private R\&D for agriculture. 2020. Available online: https: / / www.nber.org/chapters/c14298.pdf (accessed on 29 September 2020).

4. Pimentel, D.; Culliney, T.W.; Buttler, I.W.; Reinemann, D.J.; Beckman, K.B. Low-input sustainable agriculture using ecological management practices. Agric. Ecosyst. Environ. 1989, 27, 3-24. [CrossRef]

5. Sarkar, D.; Kar, S.K.; Chattopadhyay, A.; Shikha; Rakshit, A.; Tripathi, V.K.; Dubney, P.K.; Abhilash, P.C. Low input sustainable agriculture: A viable climate-smart option for boosting food production in a warming world. Ecol. Indic. 2020, 115, 106412. [CrossRef]

6. Altieri, M.A. Linking ecologists and traditional farmers in the search for sustainable agriculture. Front. Ecol. Environ. 2004, 2, 35-42. [CrossRef]

7. Brodt, S.; Six, J.; Feenstra, G.; Ingels, C.; Campbell, D. Sustainable agriculture. Nat. Educ. Knowl. $2011,3,1$.

8. Thompson, P.B. Emerging (food) technology as an environmental and philosophical issue in the era of climate change. In Food, Environment and Climate Change: Justice at the Intersections; Gilson, E., Kenehan, S., Eds.; Rowman and Littlefield: Lanham, MD, USA, 2019; pp. 195-211.

9. Wise, T.A. Eating Tomorrow: Agribusiness, Family Farmers, and the Battle for the Future of Food; The New Press: New York, NY, USA, 2019.

10. Duncan, I.J.H.; Rollin, B.E. Farm animal welfare in Canada: Major problems and prospects. In What's on Your Plate? The Hidden Costs of Industrial Agriculture in Canada; World Society for the Protection of Animals: Toronto, ON, Canada, $2012 ;$ pp. 135-160.

11. Garnett, T.; Appleby, M.C.; Balmford, A.; Bateman, I.J.; Benton, T.G.; Bloomer, P.; Burlingame, B.; Dawkins, M.; Dolan, L.; Fraser, D.; et al. Sustainable intensification in agriculture: Premises and policies. Science 2013, 341, 33-34. [CrossRef]

12. Schurman, R.; Munro, W.A. Fighting for the Future of Food: Activists versus Agribusiness in the Struggle over Biotechnology; U of Minnesota Press: Minneapolis, MN, USA, 2013.

13. Wynne, B. Redefining the issues of risk and public acceptance: The social viability of technology. Futures 1983, 15, 13-32. [CrossRef]

14. Sclove, R. Democracy and Technology; Guilford Press: New York, NY, USA, 1995.

15. Kearnes, M.; Grove-White, R.; Macnaghten, P.; Wilsdon, J.; Wynne, B. From bio to nano: Learning lessons from the UK agricultural biotechnology controversy. Sci. Cult. 2006, 15, 291-307. [CrossRef]

16. Colantonio, A. Social Sustainability: An Exploratory Analysis of Its Definition, Assessment Methods Metrics and Tools; EIBURS Working Paper Series (2007/01); Oxford Brooks University, Oxford Institute for Sustainable Development (OISD)—International Land Markets Group: Oxford, UK, 2007.

17. Davidson, M. Social sustainability: A potential for politics? Local Environ. 2009, 14, 607-619. [CrossRef]

18. Collingridge, D. The Social Control of Technology; St. Martin's Press: New York, NY, USA, 1980.

19. Liebert, W.; Schmidt, J.C. Collingridge's dilemma and technoscience. Poiesis Prax. 2010, 7, 55-71. [CrossRef]

20. Genus, A.; Stirling, A. Collingridge and the dilemma of control: Towards responsible and accountable innovation. Res. Policy 2018, 47, 61-69. [CrossRef]

21. Mepham, B. A framework for the ethical analysis of novel foods: The ethical matrix. J. Agric. Environ. Ethic. 2000, 12, 165-176. [CrossRef]

22. Cotton, M. Evaluating the 'ethical matrix' as a radioactive waste management deliberative decision-support tool. Environ. Values 2009, 18, 153-176. [CrossRef]

23. Buckley, J.A.; Thompson, P.B.; Whyte, K.P. Collingridge's dilemma and the early ethical assessment of emerging technology: The case of nanotechnology enabled biosensors. Technol. Soc. 2017, 48, 54-63. [CrossRef] 
24. Beauchamp, T.L. The belmont report. In The Oxford Textbook of Clinical Research Ethics; Emanuel, E.J., Grady, C., Crouch, R.A., Lie, R.K., Miller, F.G., Wendler, D., Eds.; Oxford University Press: New York, NY, USA, 2008; pp. 21-28.

25. Curran, D. Risk, risk society, risk behavior and social problems. In The Blackwell Encyclopedia of Sociology; Blackwell: Oxford, UK, 2016. [CrossRef]

26. Guston, D.H. Understanding 'anticipatory governance'. Soc. Stud. Sci. 2014, 44, 218-242. [CrossRef] [PubMed]

27. Stilgoe, J.; Owen, R.; Macnaghten, P. Developing a framework for responsible innovation. Res. Policy 2013, 42, 1568-1580. [CrossRef]

28. Holbrook, J.B. Re-assessing the science-society relation: The case of the US National Science Foundation's broader impacts merit review criterion. (1997-2011). In Peer Review, Research Integrity, and the Governance of Science-Practice, Theory, and Current Discussion; Frodeman, R., Holbrook, B., Mitcham, C., Xiaonan, H., Eds.; People's Publishing House: Beijing, China, 2017; pp. 328-362.

29. Beauchamp, T.L.; Childress, J.F. The Principles of Biomedical Ethics, 7th ed.; Oxford University Press: Oxford, UK, 2012.

30. Mepham, B. Bioethics: An Introduction for the Biosciences, 2nd ed.; Oxford University Press: Oxford, UK, 2008.

31. Kaiser, M.; Millar, K.; Thorstensen, E.; Tomkins, S. Developing the ethical matrix as a decision support framework: GM fish as a case study. J. Agric. Environ. Ethic. 2007, 20, 65-80. [CrossRef]

32. Webster, J.; Bollen, P.; Grimm, H.; Jennings, M. Ethical implications of using the minipig in regulatory toxicology studies. J. Pharmacol. Toxicol. Methods 2010, 62, 160-166. [CrossRef]

33. Tangen, R. Balancing ethics and quality in educational research-The ethical matrix method. Scand. J. Educ. Res. 2013, 58, 678-694. [CrossRef]

34. Jensen, K.K.; Michalopoulos, T.; Meijboom, F.L.B.; Gjerris, M. Perceptions of ethical challenges within the low input breeds project. Food Ethic. 2017, 1, 109-125. [CrossRef]

35. Thompson, P.B. Agricultural ethics-Then and now. Agric. Hum. Values 2015, 32, 77-85. [CrossRef]

36. Kikuti, M.; Deen, J.; Pinilla, J.C.; Corzo, C.A. Understanding Sow Mortality: Part 1. College of Veterinary Medicine, University of Minnesota. 2021. Retrieved March 10, 2021. Available online: https://vetmed.umn.edu/sites/vetmed.umn.edu/files/shmp_20 20121.30_understanding_sow_mortality_part_1.pdf (accessed on 16 December 2021).

37. Knauer, M.; Stalder, K.; Baas, T.; Johnson, C.; Karriker, L. Physical conditions of cull sows associated with on-farm production records. Open J. Veter. Med. 2012, 2, 137-150. [CrossRef]

38. Sasaki, Y.; Koketsu, Y. Mortality, death interval, survivals, and herd factors for death in gilts and sows in commercial breeding herds1. J. Anim. Sci. 2008, 86, 3159-3165. [CrossRef] [PubMed]

39. Hostiou, N.; Fagon, J.; Chauvat, S. Impact of precision livestock farming on work and human-animal interactions on dairy farms. A review. Biotechnol. Agron. Soc. Environ. 2017, 21, 268-275.

40. Benjamin, M.; Yik, S. Precision livestock farming in swine welfare: A review for swine practitioners. Animals 2019, 9, 133. [CrossRef]

41. Glaser, B.; Strauss, A. The Discovery of Grounded Theory; Aldine: Chicago, IL, USA, 1967.

42. Boyatzis, R. Transforming Qualitative Information: Thematic Analysis and Code Development; Sage: Thousand Oaks, CA, USA, 1998.

43. Lincoln, Y.; Guba, E. Naturalistic Inquiry; Sage: Newbury Park, CA, USA, 1985.

44. Bruner, J. The narrative construction of reality. Crit. Inq. 1991, 18, 1-21. [CrossRef]

45. Isch, C. From Farm to Factory: How Consumer Demand for Cheap Food Has Affected the Practice of Farming. Available online: https:/ / iu.pressbooks.pub/foodfiberfashionfa19/chapter/from-family-to-factory-farm-calvin/ (accessed on 8 May 2021).

46. Rowe, E.; Dawkins, M.S.; Gebhardt-Henrich, S.G. A systematic review of precision livestock farming in the poultry sector: Is technology focussed on improving bird welfare? Animals 2019, 9, 614. [CrossRef] [PubMed]

47. Sparrow, R.; Howard, M. Robots in agriculture: Prospects, impacts, ethics, and policy. Precis. Agric. 2020, 22, 818-833. [CrossRef]

48. Bos, J.M.; Bovenkirk, B.; Fiendt, P.H.; van Dam, Y.K. The quantified animal: Precision livestock farming and the ethical implications of objectification. Food Ethics 2018, 2, 77-92. [CrossRef]

49. Werkheiser, I. Technology and responsibility: A discussion of under examined risks and concerns in Precision Livestock Farming. Anim. Front. 2020, 10, 51-57. [CrossRef] [PubMed]

50. Werkheiser, I. Precision livestock farming and farmers' duties to live-stock. J. Agric. Environ. Ethics 2018, 31, 181-195. [CrossRef]

51. Finucane, M.L.; Slovic, P.; Mertz, C.K.; Flynn, J.; Satterfield, T.A. Gender, race, and perceived risk: The 'white male' effect. Health Risk Soc. 2000, 2, 159-172. [CrossRef]

52. National Research Council. Enhancing the Effectiveness of Team Science; National Academies Press: Washington, DC, USA, 2015. [CrossRef]

53. Klayman, J. Varieties of confirmation bias. Psychol. Learn. Motiv. 1995, 32, 385-418.

54. Mepham, B.; Kaiser, M.; Thorstensen, E.; Tomkins, S.; Millar, K. Ethical Matrix Manual; LEI, Onderdeel van Wageningen UR: Wageningen, The Netherlands, 2006.

55. Chesebro, J.L. The relationship between listening styles and conversational sensitivity. Commun. Res. Rep. 1999, 16, $233-238$. [CrossRef]

56. Slovic, P. Perception of risk. Science 1987, 236, 280-285. [CrossRef] [PubMed]

57. Holman, B.; Elliott, K.C. The promise and perils of industry-funded science. Philos. Compass 2018, 13, e12544. [CrossRef] 